\title{
Improving the Mechanical Properties of Aisi 2205 Duplex Stainless Steel by Cryogenic Treatment Process
}

\author{
Shivani Koppula ${ }^{1 *}$, Aakula Rajkumar $^{2}$, Siram Hari Krishna ${ }^{3}$, Reddi Sai Prudhvi ${ }^{4}$, S. Aparna ${ }^{5 *}$, Ram Subbiah $^{5 *}$ \\ 1,2,3,4 Under Graduate Students, Gokaraju Rangaraju Institute of Engineering and Technology, Hyderabad, India \\ ${ }^{5}$ Associate Professor, Gokaraju Rangaraju Institute of Engineering and Technology, Hyderabad, India
}

\begin{abstract}
The Duplex stainless steel AISI 2205 is well known for its corrosion resistance, applicable to high pitting and stress resistance. Cryogenic treatment is chosen to boost the mechanical properties of AISI 2205 Stainless Steel. The specimens undergo cryogenic treatment, one of them being treated to the saturated limit. For comparison purpose, one specimen is kept as untreated. Wear test will be conducted at a constant speed and variable load by a pin on disc wear testing apparatus. Wear test is completed to assess the capability of utilizing a specific surface building innovation to diminish wear for a particular application and to research the impact of treatment conditions on the wear execution, so upgraded surface treatment conditions can be figured it out. Eventually, all specimens were undergone with Scanning Electron Microscope analysis.
\end{abstract}

\section{Introduction}

Stainless steel is the main material of iron-based alloys with a minimum quantity of around $11 \%$ chromium, a composition that prevents iron from corrosion and provides heat resistance. Relevant shapes of stainless steel include components $\mathrm{C}$ (from 0.03 to over 1.00 per cent), N, Al, Si, S, Ti, Ni, Cu, Se, Nb, and Mo. Stainless steel is $100 \%$ recyclable, consisting of $60 \%$ recycled materials and $40 \%$ of end-of-life products [1-3].

Stainless steel is used for applications that resist corrosion and heat. Stainless steel, combined with strong mechanical properties, meets this entire necessity. Stainless Steel has good oxidation and corrosion resistance. Based on metallurgical structure stainless steel are classified as martensite stainless steels, ferritic stainless steels, precipitation stainless steel, Austenitic stainless steels and duplex stainless steel $[5,6]$.

Duplex stainless steels are made from chromium (18$26 \%$ ) nickel (4-7\%), molybdenum (0-4\%), copper, and iron. Duplex stainless are easily weldable. But to preserve the right balance of austenite and ferrite some precautions has to be taken. These are ferromagnetic and at very low temperatures they undergo transitional effect. The thermal expansion of this material is more than austenitic material and less than ferritic stainless steels while other thermal properties are the identical as plain carbon steels. Greater forces are required compared to austenite stainless steel. Formability is acceptable for this material. In addition to the improvised corrosion resistance with the 300 series stainless steels and duplex steels also have higher strength. Stainless steel is the main material of iron-based alloys known for its heatresistance and corrosion [12]. Even though stainless steel has a vital range of properties, hardness of stainless steel has very high but low wear resistance and corrosion. Duplex stainless steel has a higher resistance to pitting, crevice corrosion and stress corrosion cracking. Duplex stainless steel has very less thermal expansion and very high conductivity of heat compare to austenitic steels. Duplex stainless steels are used in many ways like production of pipe and oil or gas transportation. They are also used in structural and mechanical components. They can be used in heat exchangers and cooling pipes. There are many benefits of stainless steel like it is lightweight, reasonably priced, has good strength and many other benefits $[13,14]$. With an alluring mix of the highquality mixture, some of the properties would appear like corrosion resistance. Moderate weldability of the material would offer incredible potential of duplex stainless steels of all over the industry [15].

\section{Experimental Procedure}

Table 1: AISI 2205 Stainless Steel Composition

\begin{tabular}{|c|c|}
\hline Metals & Composition (\%) \\
\hline Carbon $(\mathrm{C})$ & $0.25 \%$ \\
\hline Manganese $(\mathrm{Mn})$ & $2.0 \%$ \\
\hline Silicon $(\mathrm{Si})$ & $1.5 \%$ \\
\hline Sulphur $(\mathrm{S})$ & $0.03 \%$ \\
\hline Phosphorous $(\mathrm{P})$ & $0.045 \%$ \\
\hline
\end{tabular}

\footnotetext{
*Corresponding author: shivanikoppula11@gmail.com
} 


\begin{tabular}{|c|c|}
\hline Nickel (Ni) & $6 \%$ \\
\hline Chromium $(\mathrm{Cr})$ & $22 \%$ \\
\hline Molybdenum & $3 \%$ \\
\hline
\end{tabular}

\section{CRYOGENIC HEAT TREATMENT}

Cryogenic treatment of steels helps in developing many tribological properties. One of the most widely recognized in cryogenic treatment is an expansion in wear obstruction of prepares. Using cryogenic heat treatment over ordinary heat treatment helps producers to achieve better properties like good wear resistance. Cryogenic heat treatment is a permanent process. At cryogenic temperature, the treatment advances the change of held austenite into martensite [4]. The cryogenic treatment has many advantages and gives dimension solidness to the material by improving properties like wear obstruction, strength, hardness. The issue of held austenite after undergoing regular warmth treatment still exists. In the conventional quench hardening process, the steels were heated and allowed to soak for some period of time and oil quenched at normal room temperature. This quick cooling from solidifying temperature causes to change into austenite. The austenite is a soft allotropic form of iron when cooled transforms into other phases. This transformation does not depend on time and diffusionless and also no chemical composition occurs during transformation. It smoother the change of adventure into ferrite and celebrate. The solidifying of material depends on the arrangement of martensite. Other phases may be formed if martensite is not formed. At lower temperatures this retained austenite is insecure. Cryogenic treatment is the process of treating workpieces to cryogenic temperatures (i.e. below $-190{ }^{\circ} \mathrm{C}\left(-310{ }^{\circ} \mathrm{F}\right)$ ) to remove residual stresses and improve wear resistance on steels and even composites. The heat treatment is conducted on 12 out of 13 specimens, 1 specimen for comparison purposes is kept untreated. The heat treatment is carried out for varying durations, the average length to the saturated temperature.

The Other hypothesis of steels are based on being strengthen by sub-microscopic carbide precipitation. It's said an extra advantage is the reduction of internal martensite stresses formed during precipitation of carbide, which reduces of microcrack tendencies. The cryogenic process is more complex than that, starting with increasing the temperature to 200 degrees $\mathrm{F}$, lowering it to -300 degrees $\mathrm{F}$, then normally going down to +300 degrees $\mathrm{F}$ and then to room temperature. The final part of the process must be completed. The science behind cryogenic processing is the same as the science behind traditional thermal treatments, regardless of the temperature range.

\section{WEAR TEST}

The test method involves a laboratory technique for determining material wear, using a pin-on-disk tool (Fig. 1(a)) during the sliding[11]. Under nominally nonabrasive conditions materials are tested in pairs. The key areas of experimental interest are defined by using this type of wear measurement apparatus. The friction coefficient is also calculated. The rate of Wear is calculated from the height loss technique and expressed in terms of wear loss per unit volume of wear sliding distance.

In this Wear test, two specimens are used to perform Pin on the disc. In the present experiment the parameters such as speed, time and load are kept constant throughout for all the experiments. Two specimens are used to perform the pin on disc wear test. The sliding pin is revolving against the disc which works with continuous charge. Untreated here with 6 treated samples shall be replaced for wear check immediately. Wear results for the pin and disc separately are recorded as volume loss in millimetres. Residual stress is removed and wear resistance is improved on the steels.

\section{HARDNESS TEST}

Rockwell hardness tests (Fig. 1(b)) were performed under a load of $100 \mathrm{~kg}$ with treated and untreated samples. The measurements were taken at B-Scale as all samples were subjected to a steel ball indentor of 1/16'. The readings below were obtained. After the wear analysis, metallographic analysis is performed on the specimens. In the metallographic analysis, the hardness value is obtained by the Rockwell hardness testing machine. Now, the values of metallographic analysis of the heat-treated specimens are compared with the untreated specimen and the values are noted. These values give us the change in properties i.e., strength, hardness, wear resistance, ductility and softness.

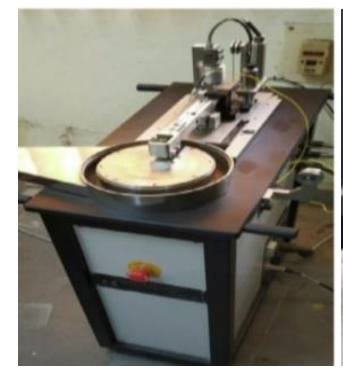

(a)

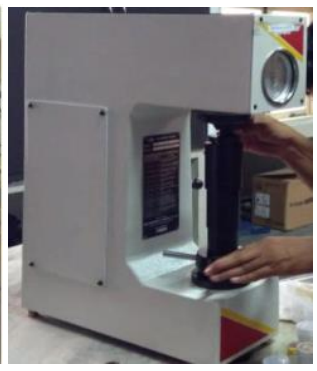

(b)
Fig. 1: a) Pin on Disc Apparatus, b) Rockwell Hardness Test

\section{Results and discussions}

To determine the thickness of the nitride layer and mechanical properties, the specimen 2205 duplex stainless steel material, both handled and untreated (Fig. 2(a)). From the findings of the scanning electron microscope, further material peeling from the untreated specimen was discovered. As the time of heat treatment increases, wear decreases and wear loss decrease on the stainless-steel material (Fig. 2(b)). There is less wear of material when it is exposed to stack. Along these lines wear opposition of the material increments, improving the property of malleability in hardened steel material and in this way expanding the hardness (Fig. 2(c)). In this section, the aftereffects of different examinations performed to break down the impact of Hardening on the microstructures, hardness and wear conduct of 2205 
evaluation treated steel (Fig. 2(d))alongside the consequences of optical microscopy and filtering electron magnifying instrument.

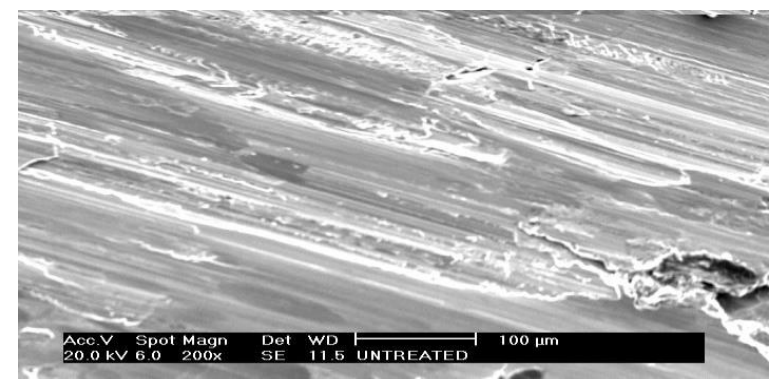

(a)

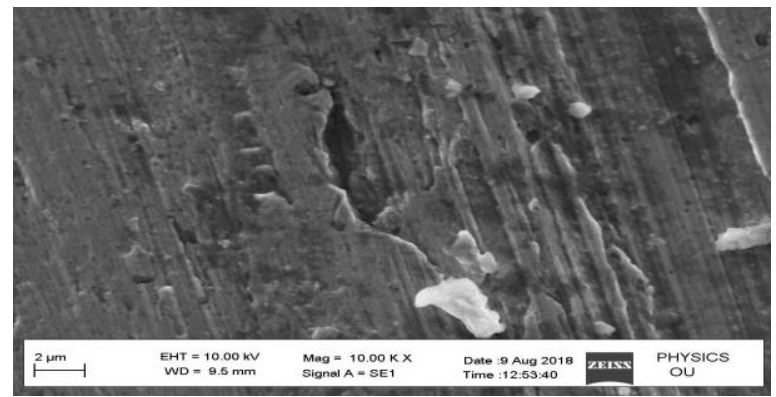

(b)

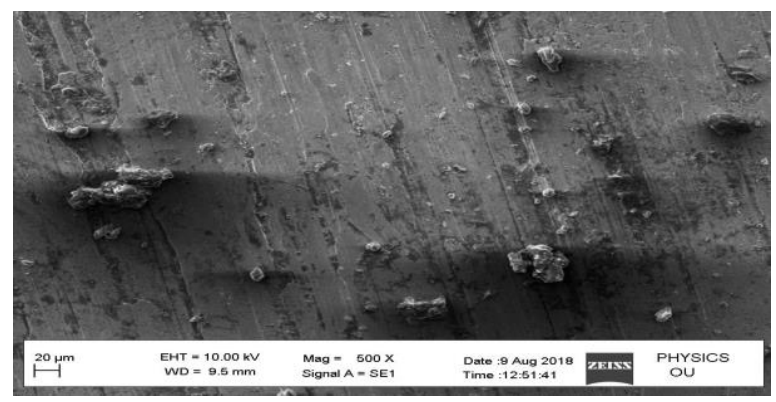

(c)

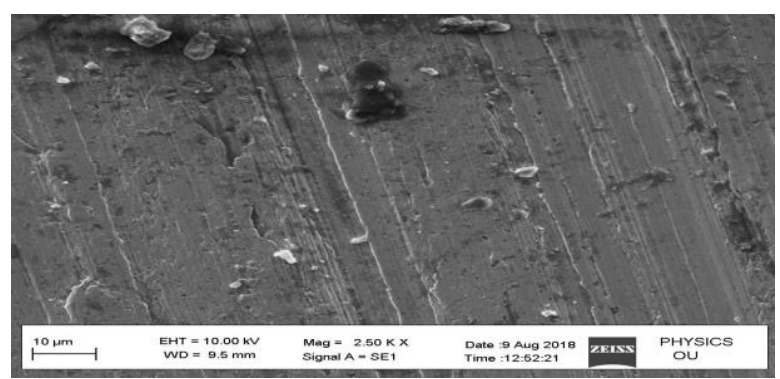

(d)

Fig. 2: Image of SEM (a) Untreated Sample (b) 60 minutes Sample (c) 120 minutes Sample (d) 180 minutes Sample before wear test.

From the wear studies, the observed wear loss of Hardening specimens was found to be in the range of 3.375 to $1.75 \mathrm{~mm}^{3}$ (Fig. 3(a)) and in tempering specimen, it was found to be 1.125 to $2.5 \mathrm{~mm}^{3}$ (Fig. 3(b)) No case depths were detected from the sampledepth tests for an untreated specimen. The case depth rises in the hardening specimens from 11.5 microns to 14 microns (Fig. 3(c)), and in the tempering specimens from 7.5 microns to 9.5 microns (Fig. 3(d)). From the overall tests and measurements carried out based on the wear loss test, it was concluded that the wear resistance improved, the performance of 2205 stainless steel materials improved. For the materials needed for hightemperature applications, these types of coating processes are favoured.

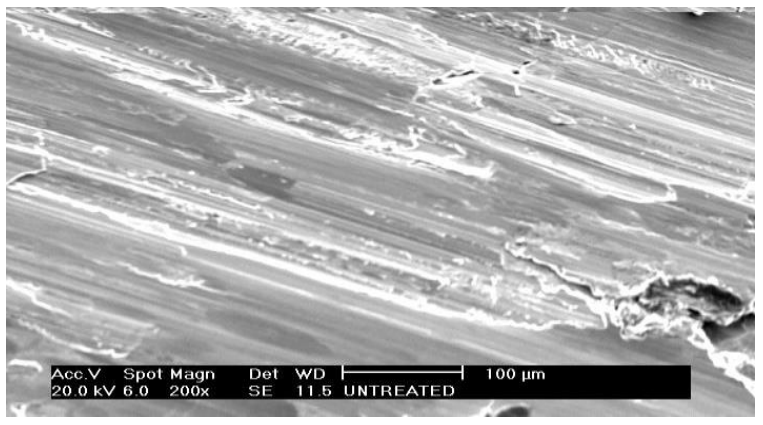

(a)

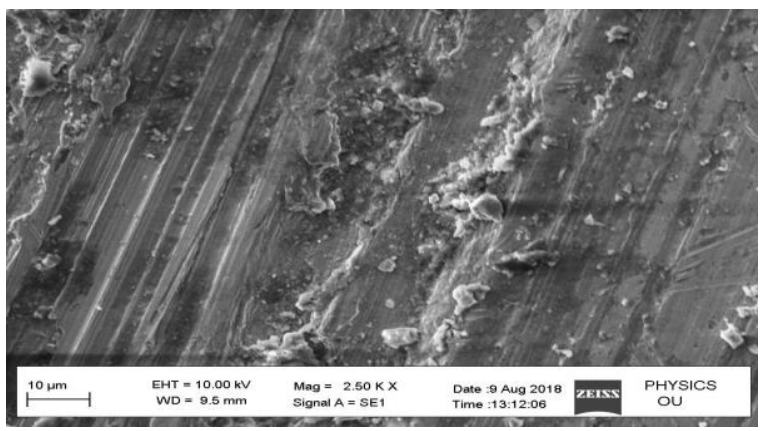

(b)

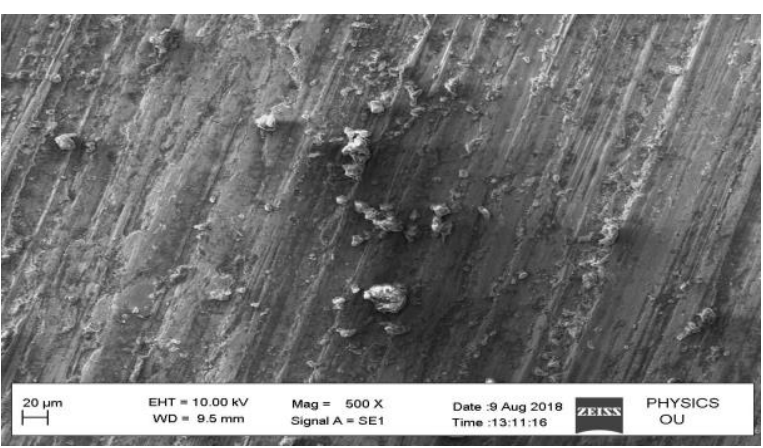

(c)

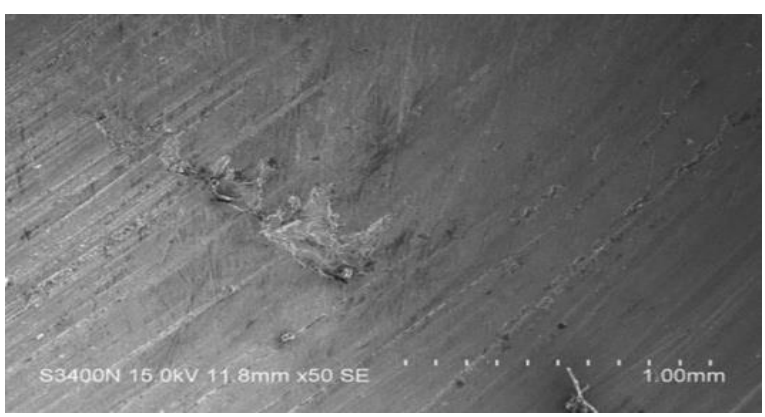

(d)

Fig. 3: Image of SEM (a) Untreated Specimen (b) Specimen 1 (c) Specimen 2 (d) Specimen 3 after wear test. 


\section{Conclusion}

For this study, 2205 grade stainless steels were treated with cryogenic heat treatment, and the wear behaviour was observed. Here a comparative analysis was performed on untreated sample handled specimens. Cryogenic is a feasible technique to increase the resistance of stainless steel materials to wear. The current examination concentrated on exploring the impact of the AISI 2205 tempered steel material on microstructure, hardness and wear opposition.

Cryogenic specimens show very minute micros etch pits in SEM analysis. They are visualized in the compound layer which shows the irregular distribution of particles of carbon and nitride. The results of this work indicate that the cryogenic heat treatment has effectively improved its wear resistance. When it is compared with the untreated specimen the wear resistance for cryogenic is observed to high, as it has very even nitride distribution on the surface.

\section{References}

1. J. Wang, Z. Li, D. Wang, S. Qiu, F. Erns, J.M.Science, Volume 128, (2017).

2. Y. Peng, C. Chen, X. Li, J. Gong, Y. Jiang, Z. Liu, Surface and Coatings Technology Volume 328, (2017).

3. G.Maistroa, C.Oikonomoua, L.Rogströmb, L.Nyborga, Y.Caoa, Surface, Volume 322, (2017).

4. Baloji, D., Anil, K., Satyanarayana, K., Singh, S. K., \& Naik, M. T. Material Today 18, 4475-4481. (2019)

5. M. R. Jean, L. Courouaua, M. Tabarantc, C. B. M. L. Giorgib, Journal of Nuclear Materials, Volume 500, Pages 337-348, (2017).

6. X. Zhang, J. Wang, H. F. D. Pan, Applied Surface Science, Volume 440, (2017).

7. Z. D. N. Guermazia, Ahmed K. M. G. N. Haddara, Materials Science and Engineering: A, Volume 696, (2017)

8. A.Dalmaua, C.Richard, A.Igual - Muñozac Tribology, International, Volume 121, (2018).

9. Yang Yanga, M.F.Yana, S.D.Zhanga, J.H.Guoa, S.S.Jianga, D.Y.Lib, Surface and Coatings Technology Volume 333, (2018).

10. A. Paulo, T. Arthur, S. Nishikawaa, L. B. Varelaa, Thin Solid Films, Volume 644, (2017).

11. Manikonda, R. D., Kosaraju, S., Raj, K. A., \& Sateesh, N., Material Today 5, 20104-20109. (2018).

12. Suresh Kumar Tummala, Dhasharatha G, E3S Web of Conferences 87, 01030 (2019)

13. D.S.Rong, J.M.Gong, Y.Jiang, Procedia Engineering, Volume 130, (2015).

14. Rajagiri A, MN Sandhya, Nawaz S, Suresh Kumar T, E3S Web of Conferences 8701004 (2019).

15. N. Uedaa, N. Yamauchia,T. Sonea, A. Okamotoa, M.Tsujikawab, Volume 201, Issues 9-11, (2005). 